\title{
Sobre adaptaciones teatrales de novelas cervantinas. Un caso de comedia decimonónica: Rinconete y Cortadillo de Vicente Colorado
}

\author{
Juan Manuel Escudero BaztáN*
}

\begin{abstract}
Resumen
Este trabajo estudia por primera vez una adaptación teatral de la novela ejemplar de Cervantes, Rinconete y Cortadillo, de finales del siglo XIX escrita por el dramaturgo Vicente Colorado. La comedia, apenas leída, mantiene puntos en común con la obra cervantina, a la vez que presenta diferencias muy acusadas con su modelo tanto en la conclusión como en el desarrollo novedoso de una trama sentimental.
\end{abstract}

Palabras clave: adaptación teatral; novela; Cervantes; Rinconete y Cortadillo; siglo XIX; Vicente Colorado.

Title: On theatrical adaptations of Cervantes' novels. An example of a nineteenth century comedy: Vicente Colorado's Rinconete y Cortadillo

\begin{abstract}
This paper analyzes for the first time a theatrical adaptation of an exemplary novel of Cervantes, Rinconete y Cortadillo, written in the late nineteenth century by the playwright Vicente Colorado. The comedy, barely read, maintains points in common with the Cervantes' work, while it presents very sharp differences like a different end and a new development of a sentimental plot.
\end{abstract}

Keywords: Theatrical Adaptation; Novel; Cervantes; Rinconete y Cortadillo, Nineteenth Century; Vicente Colorado.

* GRISO, Universidad de Navarra. jescudero@unav.es / ORCID iD: https://orcid.org/0000-00030089-2785. 


\section{Cómo citar este artículo / Citation}

Escudero Baztán, Juan Manuel (2018). «Sobre adaptaciones teatrales de novelas cervantinas. Un caso de comedia decimonónica: Rinconete y Cortadillo de Vicente Colorado», Anales Cervantinos. 50, pp. 195-209, https://doi.org/10.3989/anacervantinos.2018.008.

Muy escasos son los estudios que se han ocupado de ofrecer una imagen de conjunto sobre la reescritura dramática de las Novelas ejemplares de Cervantes $^{1}$. Hasta la fecha solo el meritorio trabajo de Katerina Vaiopoulos (2010a y 2010b) ofrece un panorama lo suficientemente amplio como para ser tenido en cuenta ${ }^{2}$, aunque circunscrito a la dramaturgia del Siglo de Oro. No obstante, el esquema que presenta Vaiopoulos ${ }^{3}$ muestra excesiva vaguedad: uno, porque la base teórica sobre la que sustenta su análisis no apura del todo las relaciones intertextuales que se establecen entre las diferentes reescrituras dramáticas; y segundo, porque esa falta de concretización no advierte cambios sustanciales más allá de las técnicas tradicionales del estudio comparado de textos diferentes. Pero el objeto de estas páginas es mucho más modesto. Y no pretende fijar pautas de estudio para las posibles relaciones genéticas entre las novelas ejemplares cervantinas y sus secuelas posteriores. Su punto de partida es el análisis de una obra dramática escrita en 1895 por Vicente Colorado y Martínez - periodista, poeta y dramaturgo español, nacido en Valladolid el 19 de abril de 1850 y fallecido en Madrid el 10 de septiembre de $1904^{4}$ _ , una adaptación teatral de la novela ejemplar cervantina

1. Hay trabajos parciales como los de Montero Reguera (1993); Rey Hazas (1999); Fernández Ferreiro (2011); Arellano (2012); y Escudero Baztán (2016), que inciden sobre aspectos particulares de adaptaciones teatrales de las novelas cervantinas.

2. El trabajo de Jurado Santos (2005) es un catálogo bibliográfico de obras dramáticas derivadas de novelas cervantinas.

3. Resumo muy brevemente el marco teórico que sustenta su análisis. Aplicando parte de la teoría de Genette, Vaiopoulos comienza su estudio definiendo las conexiones hipertextuales, como cada una de las diferentes conexiones que relaciona un texto B (hipertexto o texto de segundo grado) con un texto A que lo precede (conocido como hipotexto). Sobre estos presupuestos contempla Genette varias categorías entre las que destaca la transposición ('decir lo mismo de modo distinto'). Y Vaiopoulos contempla dos tipos de transposiciones siguiendo a Genette, las que llama completas, donde hay una transformación del hipotexto en el hipertexto, y las que denomina como parciales (toman una parte del hipotexto para crear un hipertexto con un texto nuevo). En relación a esta transposición cabe señalar, de paso, como uno de sus componentes esenciales, el proceso de dramatización o transmodalización intermodal que supone el paso del modelo de representación diegético-mediato al mimético-inmediato, que en otras palabras consiste básicamente en la eliminación del narrador, y en el desarrollo de un sistema de transformación cuantitativa que tiende hacia la amplificación de la materia narrativa, cuando se ve esta sometida al proceso de dramatización, que Genette atribuía erróneamente a la versificación polimétrica del teatro áureo sin tener en cuenta que era una marca formal externa no relacionada directamente con el volumen de la narración.

4. Un año antes de fallecer se publicó su traducción (del francés) de la Historia del materialismo de Federico Alberto Lange (Daniel Jorro, Madrid 1903, 2 vols.), que sigue la traducción francesa de 1877-1879 de Pommerol, realizada sobre la segunda edición alemana. Esta versión forma parte de la Biblioteca Científico-Filosófica, para la que Vicente Colorado también vertió al español Ensayo acerca de la imaginación creadora de Théodule Ribot, Errores científicos de la Biblia de Émile Ferrière, 
Rinconete y Cortadillo. La obra dramática de Vicente Colorado es prácticamente desconocida ${ }^{5}$ hoy día para el gran público e incluso - me atrevería a decir-para el lector especializado. Más de la mitad de su producción dramática fue publicada y no representada ${ }^{6}$, como se desprende de algunos comentarios insertos en notas necrológicas laudatorias, publicadas en distintos periódicos tras su deceso:

Era este escritor un verdadero poeta dramático; quizás por esto, por ser ante todo poeta, sus dramas no tuvieron de las empresas, acostumbradas a ver en la escena triunfante el prosaísmo, la aceptación que merecían. Colorado escribió muchas comedias y todas en verso. Para él la prosa era la corrupción del teatro ${ }^{7}$. Sus obras representadas fueron De carne y hueso, El padre nuestro, excelente traducción de Copée, y Día de prueba, en colaboración con el que escribe estas líneas. Sus mejores comedias son las no representadas. Entre ellas recuerdo $\mathrm{El}$ Credo, obra de tesis religiosa, escrita con singular vigor y valentía. Rinconete y Cortadillo, sacada de la celebre novela de Cervantes, y Francisca de Rímini, obra en que campea alta inspi-

Lo bello: ensayo acerca del origen y la evolución del sentimiento estético de Luciano Bray, El dormir y el soñar de Joseph Delboeuf. Más detalles bio-bibliográficos pueden consultarse en < http://www. filosofia.org/ave/001-/a292.htm>.

5. Escasísimas son, por ejemplo, las alusiones a la obra que aquí se estudia. López Mozo (2015) la menciona a la hora de precisar los precedentes a la puesta en escena de las obras cervantinas entre 1950 y 2014.

6. Una perspectiva libresca que se le achacaba como defecto en su estreno como dramaturgo ya en su primera obra De carne y hueso, drama en tres actos y en verso, estrenado en el Teatro Español el 21 de noviembre de 1883: «Alguien ha dicho, al hablar de la inexperiencia teatral del Sr. Colorado y de las privativas condiciones de su obra, que hasta en los menores incidente del desarrollo del drama "aparece el hombre que, viviendo siempre entre libros, solo en ellos aprendió la vida, las pasiones y los dramas sociales"» (ver la crítica de Manuel Cañete que se incluye en la primera edición de la obra (Colorado 1897: 19). A pesar de que la acogida de esta obra temprana no fue mala, no volvió a presentar una nueva hasta más de una década después, cuando estrena en el Español, el 16 de enero de 1894, otro drama de nuevo en tres actos y en verso: Día de prueba, escrita en colaboración con Francisco Fernández Villegas. La obra dramática de Vicente Colorado tuvo desigual fortuna sobre los escenarios, pues un buen número de sus obras nunca llegó a ser representado. Tras su fracaso en el estreno de Yo pecador, optó por poner cierre a su producción con la publicación en papel de su Teatro, dividido en dos tomos. El primero de ellos, publicado en febrero de 1897, editado junto a una carta que envió Alarcón al autor tras el estreno de De Carne y hueso a modo de proemio y un estudio crítico de Manuel Cañete acerca de esta obra, contiene el drama referido y el cuadro dramático Yo pecador. El segundo tomo, publicado en el mes de octubre de 1897, recoge dos obras que no llegaron nunca a las tablas: el drama en tres actos Francisca de Rímini y el cuadro baturro en un acto titulado El acta. Para más datos remito a la bibliografía final.

7. Esta apasionada defensa del verso sobre cualquier otra forma de creación literaria fue ponderada por ejemplo por Unamuno, quien en la revista Nuevo mundo del 14 de noviembre de 1924 hacía el siguiente comentario: «Mi amigo Vicente Colorado — ¡cómo se le ha olvidado ya!- - fanático de la versificación — no toleraba que se hiciesen dramas en prosa-, me decía cuando apareció la primera edición de mi novela Paz en la guerra que debí haber puesto en verso su final, ya que era, según él creía, pura materia poética» (Martínez Deyros 2015: 34). Y es que sus inicios literarios están íntimamente ligados a la poesía, siendo su primera publicación Glorias militares y literarias del reinado de Felipe II, un poema histórico que fue distinguido con el primer premio, regalo de S. M. el Rey, en el certamen literario llevado a cabo en Valladolid el 29 de septiembre de 1879. Su segundo y último poemario fue Besos y mordiscos (1887). No volvió a publicar ningún otro, pero sí numerosas composiciones líricas que fue diseminando en sus numerosas colaboraciones periodísticas. 
ración y encumbrada poesía. Este drama estuvo varias veces a punto de ser representado. ¿Por qué no llegó a ponerse en escena? No lo sé. Francisca de Rímini es muy superior en mérito a otras muchas obras teatrales que han dado fama y provecho a sus autores. Quizás vino tarde a la vida. Los gustos iban por otro camino, y esto explica si no justifica, el desvío que con el drama de Colorado mostraron las empresas. Tales desvíos amargaron los últimos años del escritor (Zeda 1904).

O este otro rápido apunte, que interesa más por referirse a la reescritura cervantina, del crítico teatral Dionisio Pérez (1905) a los pocos meses de su muerte:

... yo pediría a cualquier empresario, bien avenido con sus intereses, que sacase a escena una obra no representada por rarezas, que todos conocimos, de su autor, Vicente Colorado. Hablo de Rinconete y Cortadillo, obra de ambiente y de ingenio singular, donde si Cervantes no resulta enaltecido, no queda agraviado tampoco. Allí hay un hermoso relato de cómo fue armado caballero Don Quijote en la famosa venta, que justificaría plenamente la actualidad de la representación. Y honraríamos a Cervantes, haciendo justicia a aquel culto y sentido poeta, Vicente Colorado, ya que en su vida fueron pocos, muy pocos los que se la hicieron. [...] Debieran patrocinar esta idea, y buscar empresario que convirtiera su escenario en el patio de Monipodio, que es cosa harto nacional y característica ayer, hoy y mañana.

Es cierto que el teatro de Colorado fue siempre a contracorriente, y tuvo a lo largo de su vida pocas oportunidades de ser representado por continuas desavenencias con los empresarios teatrales, que atisbaban poca rentabilidad económica en los textos del vallisoletano. Se entienden así, con cierto resquemor, las líneas preliminares que encabezan precisamente su comedia Rinconete y Cortadillo bajo el significativo epígrafe «El porqué» en el que señala el autor cómo ${ }^{8}$ :

Un padecimiento crónico del estómago que me impide tragar porquerías, la imbecilidad de los cómicos, las intrigas de los que nada pueden, y las malas pasiones de los que tienen más reputación que mérito, son causas bastantes para que dé mis obras a la imprenta y no al teatro.

La comedia en cuestión es una reescritura ${ }^{9}$ de la novela cervantina que Colorado subtitula como «comedia en tres actos y en verso», dedicada a don

8. Cito siempre por la edición de la obra publicada en Madrid por B. Rodríguez Serra de 1901, señalando la página. La data que figura al final de la obra es de 1895 (p. 128: «Madrid 6 de agosto de 1895»). Pero su edición es posterior: de 1901. Ver las reseñas de Gómez de Baquero (1901) y Zeda (1901). También el registro de esta obra que aparece en la Revista de Archivos, Bibliotecas y Museos (V, núm. 5, 1901: 361).

9. La reescritura en la dramaturgia del Siglo de Oro ha sido objeto de numerosos estudios en los últimos años. Sus aproximaciones teóricas pueden aplicarse a otros ejemplos posteriores. En todo caso cabe hacer deslindes terminológicos básicos entre lo que se entiende por intertextualidad y reescritura. Fernández Mosquera señala con acierto que «detrás de toda reescritura se esconde un proceso 
Marcelino Menéndez y Pelayo. El modelo cervantino parece ya demasiado alejado del supuesto horizonte de expectativas del público decimonónico (a punto de expirar la centuria), lo que determina una perspectiva diferente en el tratamiento de la materia novelada a la que cabría encontrar en una reescritura más próxima en el tiempo a la novela cervantina. Todo este proceso implica de forma global alteraciones profundas a partir del trasvase intergenérico, tanto en la búsqueda de cierta originalidad con respecto al modelo, como en su sumiso acatamiento ${ }^{10}$. En este caso, el alejamiento del modelo cervantino determina una fidelidad sui generis al texto, visible en algunas marcas formales que merecen al menos una apostilla siquiera superficial, a las que cabe añadir la aparición de motivos que apuntan hacia una especie de conexión sentimental no solo con la novela ejemplar sino con el Quijote y algunos de los más leídos poemas cervantinos. Por otra parte, también son notables los cambios que hace Colorado en su escritura con respecto a su modelo, derivados, en parte, por la necesidad de dar mayor preponderancia a la acción dramática, a la eliminación de marcas de excesiva coetaneidad (como la jerga delictiva) y a un afán por concluir la comedia de manera diferente a como lo hace Cervantes en su novela.

En líneas generales, Colorado sigue fiel a la estructura bipartita que la crítica ha venido consignando en la novela cervantina con un inicio de la novela muy cercano a la novela picaresca ${ }^{11}$, pero donde se puede observar una crítica a los presupuestos alemanianos ${ }^{12}$ - pues nada está determinado, sino que obedece al «acaso» y al más inopinado azar ${ }^{13}-$ y una segunda parte esencialmente entremesil que se desarrolla en el patio de Monipodio y que

intertextual, pero no toda intertextualidad es reescritura» (2005: 21). Para un repaso del concepto de intertextualidad en la teoría literaria del siglo xx, ver Sanz Cabrerizo (1995). Y para problemas relativos a la reescritura, Sáez (2013). A modo de cala asistemática, un trabajo ya clásico sobre reescritura es el de Ruano (1998: 35). Una puesta al día bastante actualizada es la que presenta RodríguezGallego, 2010, aunque se circunscribe al ámbito calderoniano.

10. Esta tensión generativa ya se desarrolla con plenitud dentro de las coordenadas específicas del teatro del Siglo de Oro, con sus propias normas y especificidades, como ocurre, por ejemplo, con otras reescrituras dramáticas de otras novelas cervantinas como La fuerza de la sangre y sus secuelas dramáticas; La fuerza de la sangre de Guillén de Castro y Bellvís; El agravio satisfecho de Alonso de Castillo Solórzano; y en cierta medida la comedia calderoniana No hay cosa como callar (remito, para más detalles, al trabajo de Escudero Baztán, 2013).

11. Muy obvia es, por ejemplo, su relación con el Guzmán de Alfarache cuando, al contemplar Rincón y Cortado las galeras del Guadalquivir, comenta el narrador que su «vista les hizo suspirar, y aun temer el día que sus culpas les habían de traer a morar en ellas de por vida» (171). Las evidentes relaciones entre la novela alemaniana y las novelas ejemplares cervantinas es todavía más patente en el Coloquio de los perros. Remito al excelente trabajo de Rey Hazas (2003a).

12. No es este lugar para tratar las densas y complejas relaciones de Cervantes con el género picaresco, ni en particular el alcance picaresco de Rinconete y Cortadillo. Sin ánimo de exhaustividad el interesado puede acudir a algunos de los hitos fundamentales de la bibliografía sobre esta cuestión: López Estrada (1983); Lázaro Carreter (1978); Rodríguez-Luis (1980); Sánchez (1993); Varela (1968); Ynduráin (1966); o García López (1999), entre otros.

13. Ya lo había señalado en su momento Blanco Aguinaga (1957), al poner de relieve que el realismo cervantino, totalmente diferente al de Mateo Alemán, plenamente abierto, libre y tolerante, no podía encajarse en los estrechos moldes del género picaresco. 
descubre la existencia y el funcionamiento de una cofradía de hampones sevillanos, verdadero eje de la novela, que termina con unos comentarios críticos de Rincón sobre la particularísima ética de los cofrades hispalenses, que fundamentan su necesidad de abandonar la cofradía. La primera se diferencia radicalmente de la segunda por su utilización narrativa de tiempo, espacio y acción, ya que sucede durante varios días y se mueve en espacios abiertos, ya sean campestres o urbanos, tanto durante el viaje, tras el inicial encuentro en «los famosos campos de Alcudia», como en Sevilla, donde discurre por sus diferentes calles y plazas. La segunda, en cambio, reduce extraordinariamente el ámbito espacial y temporal de su acción, pues no sale de los restringidos límites del pequeño patio de Monipodio y transcurre en apenas unas horas (Rey Hazas 2003b: 420 y ss.). La primera, en fin, remite a la novela picaresca, y la segunda al entremés de rufianes, con una estructura 'cuasidramática' con entrada y salida de personajes en incesante movimiento, como había señalado con lucidez Casalduero (1943). La primera parte de la novela, en fin, está concebida como una preparación y un preludio para la segunda, para el acceso de los dos pícaros al patio de Monipodio, donde se centra el tema principal de la novela: la existencia y el funcionamiento de una cofradía de rufianes, con un alto grado, digamos, de burocratización, tema este de la organización piramidal delictiva que atrajo poderosamente a otros escritores (piénsese en La desordenada codicia de los bienes ajenos de Carlos García). Es aquí, en la segunda parte de la novela, verdadero núcleo central y objeto final de la narración donde Cervantes no pierde la oportunidad de censurar lo que no aprueba en el Guzmán de Alfarache, porque como señala Rey Hazas (2003b: 424) ${ }^{14}$ :

... la contradictoria mezcla de religión y crimen que revela la distorsionada moral de los cofrades de Monipodio, cuyas maldades dicen poner al servicio de Dios, le viene a las mil maravillas para zaherir una vez más a Mateo Alemán, dado que éste funde en su Pícaro las sentencias teológicas más serias con los episodios más abyectos de la autobiografía de Guzmán.

Como suele ocurrir con otros modelos picarescos, y como refleja de hecho Cervantes en su novela, la inadaptación de ambos protagonistas, muy tangible a la conclusión de la obra, tiene que ver con una cuestión de carácter ético que se expresa a través de las reflexiones de Rincón sobre la necesidad de cambiar de vida, y que tienen su reflejo en la incapacidad que muestran a lo largo de la narración ambos protagonistas de entender la jerga hampesca, que viene a funcionar como discriminador formal para señalar su distanciamiento moral. En líneas generales, Colorado se sirve de todos los elementos argumentales característicos que usa Cervantes, respetando incluso su aparente factura picaresca, con algunos cambios en el orden de la secuencia-

14. La cita de Rey Hazas da de lleno en los escrúpulos cervantinos con respecto a la novela alemaniana. 
ción narrativa ${ }^{15}$, pero sin alterar los hitos fundamentales de la narración relativos al inicio de la novela y al encuentro fortuito de ambos jóvenes protagonistas y su posterior amistad; su engaño al arriero con los juegos de naipes; el robo de la bolsa con los quince escudos de oro; el acceso al patio de Monipodio; su elevación a rango de cofrades sin pasar un año de noviciado; y el desfile de todo el elenco de figuras que forman parte de la engrasada maquinaria del crimen, con sus derechos y obligaciones, incluidas las escenas, de sesgo más costumbrista, donde se cantan y bailan una serie de seguidillas. Esta concatenación de escenas en la comedia determina de igual manera la descripción calcada de los caracteres, con escasas diferencias que tienen su origen en la amplificación del argumento en aras de una mayor unidad de acción. Colorado se las ingenia para otorgar mayor cohesión a la estructura bipartita de la novela ejemplar a través de una inédita trama amorosa, a la que volveré más adelante. De hecho, la descripción de los personajes principales se ciñe - explicada en unas «Observaciones acerca de algunos personajes de esta comedia»—a las mismas caracterizaciones pergeñadas por Cervantes, señalando, de paso, que no es su intención que se tomen al pie de la letra, sino que se tengan presentes para caracterizar mejor los tipos dramáticos, sin detrimento de su belleza artística; «por mi parte, - apostilla Colorado - añado algunas observaciones que juzgo oportunas desde mi punto de vista» ${ }^{16}$. Los cambios más significativos, en este sentido, guardan relación con comentarios que afectan a los personajes que participan en esta intriga amorosa de nueva factura. Involucra a las mozas de «la casa llana», la Gananciosa y la Cariharta, cuya descripción física repite el modelo cervantino pero sobre la que Colorado añade ciertos matices que sirven para dignificar las relaciones amorosas que se van a dar entre la daifa y Cortadillo (p. 10):

Gananciosa es mucho más joven que la Cariharta, y ésta más desenvuelta, desgarrada y astrosa que aquélla; Gananciosa es de hermosura más natural, con menos afeites en la cara, más compuesta en el traje y de modales relativamente honestos.

15. Colorado segmenta su comedia en tres actos, con una extensión y un número de escenas muy dispares. De las 115 páginas que ocupa el texto de los tres actos; el primero ocupa 45 páginas (10 escenas); el segundo 38 (15 escenas); y el tercero 30 (10 escenas).

16. Baste como muestra el ejemplo de Monipodio (11), que es copia literal de la descripción cervantina (Rinconete y Cortadillo, ed. García López, 2001: 184): «Alto de cuerpo, moreno de rostro, cejijunto, barbinegro y muy espeso; los ojos, hundidos. Venía en camisa, y por la abertura de delante descubría un bosque: tanto era el vello que tenía en el pecho. Traía cubierta una capa de bayeta casi hasta los pies, en los cuales traía unos zapatos enchancletados, cubríanle las piernas unos zaragüelles de lienzo, anchos y largos hasta los tobillos; el sombrero era de los de la hampa, campanudo de copa y tendido de falda; atravesábale un tahalí por espalda y pechos a do colgaba una espada ancha y corta, a modo de las del perrillo; las manos eran cortas, pelosas, y los dedos gordos, y las uñas hembras y remachadas; las piernas no se le parecían, pero los pies eran descomunales de anchos y juanetudos. En efecto, él representaba el más rústico y disforme bárbaro del mundo». 
Y lo mismo se repite con respecto a los jaques Chiquiznaque y Maniferro (p. 11):

Chiquiznaque [...] es más descuidado de su persona, desaliñado en el traje y de modales más rudos y groseros; es un cobarde, rastrero, miedoso y asustadizo, villano, rufián y dicharachero. Maniferro es un cobarde fanfarrón, muy echado hacia atrás, que mira a todo el mundo de través, por encima del hombro, a hurtadillas, de reojo, de arriba a abajo, pero nunca de frente; es grave en la acción, tieso en la apostura, conciso de palabras, de voz campanuda y andar acompasado y breve; lleva siempre la mano puesta en el puño de la espada, con la que levanta por detrás el vuelo de la capa.

Esta férrea, sin apenas fisuras, vinculación a los modelos argumentales y de caracteres de la novela cervantina se explican en el drama no solo por una necesidad de acercamiento a su modelo — pese a los cambios inherentes al cambio de estatuto genérico - sino porque el valor primordial que quiso darle Colorado a su creación literaria está estrechamente relacionado con sus notables habilidades como versificador. Verter la prosa cervantina, con toda su riqueza de matices, al verso no le debió de resultar tarea fácil. Pero el resultado puede considerarse satisfactorio en muchos lugares, donde el octosílabo consigue reflejar, con bastante nitidez, las intenciones escriturarias cervantinas. En muchos casos se traslada la prosa cervantina con mínimas alteraciones. Esta es, de lejos, la labor más meritoria de la comedia de Colorado. Señalo por brevedad solo un par de ejemplos. En la novela cervantina se señala (p. 174):

... pero para todo hay remedio, si no es para la muerte, y el que vuesa merced podrá tomar es, lo primero y principal, tener paciencia; que de menos nos hizo Dios y un día viene tras otro día, y donde las dan las toman; y podría ser que, con el tiempo, el que llevó la bolsa se viniese a arrepentir y se la volviese a vuesa merced sahumada.

Que se plasma en la comedia de la siguiente manera (p. 47):

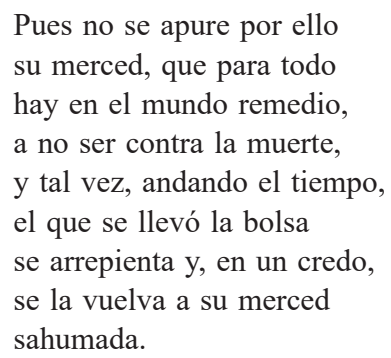

O este otro ejemplo, relativo al banquete que se prepara en el patio de Monipodio, que Cervantes lo describe en los siguientes términos (pp. 195-196): 
lo primero que sacó de la cesta fue un grande haz de rábanos y hasta dos docenas de naranjas y limones, y luego una cazuela grande llena de tajadas de bacallao frito. Manifestó luego medio queso de Flandes, y una olla de famosas aceitunas, y un plato de camarones, y gran cantidad de cangrejos, con su llamativo de alcaparrones ahogados en pimientos, y tres hogazas blanquísimas de Gandul.

Que se versifica así en el texto de la comedia (p. 83):
Tenemos bacallao frito, camarones y cangrejos de su propio llamativo de alcaparrones, ahogados en pimientos de los finos; naranjas, limones, medio queso de Flandes, corrido, y una olla de sabrosas aceitunas con aliño, con tres hogazas blanquísimas de Gandul y mucho vino.

Por otro lado, la distancia sentida entre el modelo cervantino y la comedia de Colorado permite la inserción de motivos ajenos a la novela ejemplar pero que guardan relación con el conjunto de la obra del alcalaíno. Sin duda, se trata de un homenaje de Colorado a Cervantes a través de la alusión a capítulos concretos del Quijote y a algunos de sus poemas más conocidos. En concreto, la escena inicial de la comedia se abre con una larga acotación que señala la posición exacta del mesón, situado a la izquierda de la escena, en el que se encontrarán fortuitamente Rinconete y Cortadillo ${ }^{17}$. Su visualización en escena sirve para encuadrar un diálogo entre el arriero y el mesonero, donde este último relata, en su condición de testigo y participante activo, el famoso episodio de don Quijote armado caballero en la no menos famosa venta que el hidalgo manchego confunde con un castillo (caps. 2 y 3 de la Primera parte). La perspectiva testifical del mesonero acompaña a la visión mítica del caballero, convertido ya al inicio de la obra en protagonista literario del famoso libro escrito por Cervantes. De nuevo, el mérito de Colorado estriba en la ágil versificación de la prosa cervantina ${ }^{18}$.

El segundo caso de esta alusión, relacionada con el universo cervantino, tiene una mejor trabazón en el argumento general de la comedia. Sirve para reforzar la caracterización de los dos jaques, Chiquiznaque y Maniferro, como

17. Dice la acotación: «En el primer término izquierdo, la fachada de un mesón, con soportal o cobertizo, a la entrada, mesa y asientos de madera [...] Mucha luz, mucho ambiente y mucho color» (13).

18. En la comedia, p. 16, Colorado llega, incluso, a intercalar los mismos versos que Cervantes escribe en ese cap. 2: «Nunca fuera caballero / de damas tan bien servido, / como fuera don Quijote / cuando de su aldea vino: / doncellas curaban dél, / princesas de su rocino». 
valentones pusilánimes, a través de la refundición de dos conocidos sonetos cervantinos con estrambote; el primero, titulado «A un valentón metido a pordiosero ${ }^{19} \gg$; y el segundo, seguramente su soneto más conocido, escrito en tono satírico-burlesco en relación a las exequias de Felipe II y el túmulo levantado en su honor en Sevilla ${ }^{20}$ : «Al túmulo del rey que se hizo en Sevilla ${ }^{21}$ », que de nuevo refiere el personaje del Mesonero, con bastante maña poética (p. 120) a sus interlocutores:

Esto que os ha ocurrido,

a la memoria ahora me ha traído

a un valentón de espátula y greguesco

que ejercía el oficio picaresco,

quien al ver que su bolsa le replica,

retorciendo el mostacho soldadesco,

a un corrillo llegó de gente rica.

-Den voacedes limosna, o por el cielo

que he de hacer donde no, lo que hacer suelo,

-dijo-; mas uno, que sacado había

la espada, replicó: - Y su señoría,

si limosna no alcanza,

¿qué es lo que suele hacer en tal querella?

$\mathrm{Y}$ entonces, sin tardanza,

respondió el bravonel: - Irme sin ella.

$\mathrm{Y}$ luego in continente,

dando una media vuelta aquel valiente,

caló el chapeo, requirió la espada,

miró al soslayo, fuese, y no hubo nada ${ }^{22}$.

Las divergencias, no obstante, con respecto a la novela cervantina son bastante acusadas, consecuencia, en última instancia, de la traslación intergenérica, que obliga a realizar cambios necesarios, unos porque resultan impertinentes en una comedia; otros porque, en una construcción dramática donde prima el conflicto entre personajes, se necesita desarrollar una acción principal que vertebre los distintos episodios y concluya de manera coherente de acuerdo a los derroteros tomados por el enredo.

De esta manera, resulta accesoria la presencia de aquellos episodios en los que Cervantes plasma la jerga canallesca de los habitantes del patio de Monipodio. Para Colorado resultan inapropiados, desde una posición dramática,

19. Ver el núm. 39 (410) de la edición de Sáez de las poesías cervantinas (2016).

20. Posiblemente el tono burlesco del poema no vaya solo contra el monumento funerario, sino también contra los problemas protocolarios que se dieron durante la celebración de las honras fúnebres que hicieron suspender los oficios divinos y que se ampliara la duración del catafalco de la semana inicialmente prevista a varios meses, hasta la llegada de la resolución del nuevo rey (ver la nota de Sáez a su edición de las poesías de Cervantes, 2016: 203).

21. Ver el núm. 26 (203) de la edición de Sáez de las poesías cervantinas (2016).

22. Para la fortuna de este verso en la literatura posterior es interesante el trabajo de Montero Reguera (2013). 
los juegos lingüísticos que Cervantes usa en su novela con la intención de marcar diferencias sustanciales en la condición moral de Rincón y Cortado frente a los cofrades de Monipodio. Se trata de un uso ejemplificador a partir de aspectos formales del lenguaje, elevados a la categoría de marcas de identidad grupal — no solo mecanismo cervantino-, y que aparecen en otras narraciones escritas después como La desordenada codicia de los bienes ajenos de Carlos García, que debe mucho al modelo cervantino de esta novela ejemplar ${ }^{23}$. La estrategia que sigue García en este caso es idéntica a la cervantina al escindir al supuesto narrador picaresco en dos entidades narrativas diferentes. Y romper así la ficción de la primera persona a través de un autor que funciona como transcriptor de la narración, nutriéndose de la relación de su vida que hace el protagonista de la historia, caracterizado como sujeto inhábil para cumplir su papel narratorio. Este narrador incidental, en su papel de transcriptor, se caracteriza en el inicio de la novela por una aparente transcripción automática de la narración del protagonista, pero sufre una conversión gradual como editor ficticio que admite varios grados de intromisión y edulcoramiento del relato. Lo que equipara a La desordenada codicia y a la novela ejemplar de Cervantes es que ese tácito desequilibrio en la cantidad de autoridad moral de un narrador culto y de un relator perteneciente al mundo del hampa se plantea en términos de una incomunicación basada en el desconocimiento de la jerga delictiva, el lenguaje de germanía: «Yo conozco ahora, señor mío [...] que vuestra merced no ha estudiado términos martiales, ni ha visto las coplas de la jacarandina, y así le será dificultoso entender la concusión de los cuerpos sólidos con la perspectiva de flores rojas en campo blanco ${ }^{24} \gg$. Así, queda establecido desde el inicio mismo de la novela un desnivel moral que modifica las estrategias narrativas del texto, porque reviste de autoridad al narrador-editor, y limita esa misma autoridad en el relator ${ }^{25}$. Es un caso análogo al que presenta Cervantes, y que desaparece en la reescritura teatral, paliado en este caso, como explico a continuación, a través de una estrategia de dignificación de los personajes principales a través de la inserción de una trama sentimental. Lo cual conecta con la manera convencional a la que echa mano Colorado para crear una línea argumental que dé continuidad a las dos partes principales del relato cervantino. La constitución de esta insólita historia amorosa entre Rinconete y la Gananciosa se inicia en la escena novena del primer acto (pp. 49-55) con la ayuda cómplice

23. Aspecto que todavía no ha sido estudiado lo suficiente por la crítica. Algunos elementos de esta influencia cervantina han sido destacados por Senabre (1979).

24. Cito por la edición de Roncero López (García 1996: 76).

25. Las implicaciones de este juego de voces narrativas en el fondo resulta muy interesante porque permite señalar cómo el relato se construye a la manera de una fábula moral muy cercana al Guzmán de Alfarache, donde la censura de la vida poco ejemplar de Andrés se realiza no a partir de un autorrelato confesional de arrepentimiento (pues el narrador relator nunca llega a dar muestras de arrepentimiento), sino a través de la intervención de un tercero constituido como editor que modula, cambia y cercena la calamitosa vida del protagonista de la novela (ver más detalles en Escudero Baztán, 2014). 
de la Madre Pipote, que ejerce un papel muy ceñido al modelo celestinesco. Esta subtrama sentimental no solo enlaza los tres actos de la comedia de Colorado. Tiene también un valor conclusivo final, al llevar a las tablas un remate de la peripecia que diverge en muchos aspectos de la novela cervantina. La preparación de la historia amorosa - enlazo con lo anterior-supone una especie de dignificación del protagonista y de la propia daifa ${ }^{26}$, e ilustra una diferenciación en la calidad de ambos protagonistas con el resto de personajes que pululan por la escena. Es también un anticipo de las imposibles relaciones de hermandad entre los hampones y los recién iniciados. Y también, claro, es un elemento significativo que anula las hipotéticas pretensiones picarescas del drama (si es que alguna vez las tuvo). Es probable que, de forma un tanto inconsciente, esta sublimación de Rinconete y la Gananciosa fuera ya subrayada al inicio de la comedia cuando se describe (ya se ha señalado antes) a la prostituta en términos de mayor elevación moral ${ }^{27}$. Pero no queda muy claro en el transcurso de la comedia que Colorado respete esa perspectiva moralizadora, porque inserta después algunas escenas donde se insiste en la vergonzante promiscuidad de la daifa (pues al fin y al cabo ese es su oficio), como sentencia la Madre Pipota (p. 60):

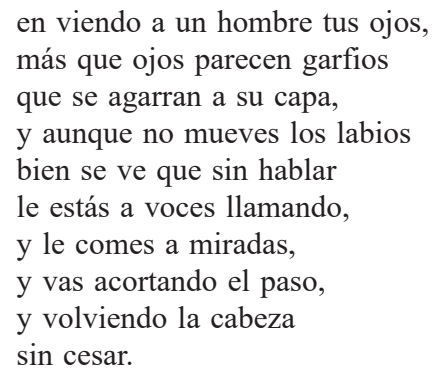

Sea como fuere, el remate de la historia amorosa conlleva un desenlace distinto al de la novela ejemplar en Cervantes, que deja en el aire el abandono de la cofradía de Monipodio, con una coda final tópica en los remates narrativos de la época («llevado de sus pocos años [Rinconete] y de su poca experiencia, pasó con ella adelante algunos meses, en los cuales le sucedieron cosas que piden más luenga escritura, y así se deja para otra ocasión contar

26. «Rinconete: Pues todavía hay un ser / que más perfección encierra / que el mar, el cielo y la tierra. / CoRtadillo: ¿Es posible? Rinconete: La mujer. / Sin darme cuenta viví / hasta hoy de que vivía, / y cuanto hacía, lo hacía / sin conciencia, porque sí. / Pero al ver a Gananciosa, / sentí como un aleteo / del corazón, y un deseo, / una ansiedad, una cosa / inexplicacable y sin nombre / de entusiasmo y de cariño, / y sin dejar de ser niño, / por vez primera he sido hombre; / y comprendí que tenía / sentidos, y alma, y pasión / para amarla, y corazón / también para hacerla mía» (57).

27. Recuérdense las apostillas que hace Colorado a la descripción cervantina del personaje: «Gananciosa es mucho más joven que la Cariharta, y ésta más desenvuelta, desgarrada y astrosa que aquélla; Gananciosa es de hermosura más natural, con menos afeites en la cara, más compuesta en el traje y de modales relativamente honestos» (10). 
su vida y milagros ${ }^{28} \gg$. Colorado se encarga de desarrollar de manera dramática y llevar a escena el momento postrero de la ruptura de las relaciones 'pseudocontractuales' de ambos protagonistas con los criminales sevillanos. Colorado cierra de forma deliberada la supuesta inconcreción cervantina con la leva hacia tierras americanas que sufre Rinconete, tras la delación de un falso Maniferro devorado por los celos. No zarpará solo. Irá finalmente acompañado de la Gananciosa, con lo que esto tiene de consolidación de su historia sentimental. La comedia concluye, así, con un final feliz, y con el abandono de ambos amantes de la asfixiante atmósfera del escurridizo Monipodio y sus secuaces. En una simétrica disposición de los avatares en este final esperanzador, la salvación moral de Cortadillo se realiza a través de sus expectativas de medro a través de su nueva condición de soldado.

Es, en fin, una victoria del amor y el prometedor inicio de una nueva vida, no exento de ciertos tonos ambiguos (p. 128):

¡No más naipes! ¡no más dados!

¡a las Indias! ¡a los Andes!...

¡a cortar bolsas más grandes!

¡Seamos buenos soldados!

que recuerda mucho a la lapidaria frase final del Buscón quevediano: «Nunca mejora su estado quien muda solamente de lugar y no de vida y de costumbres $^{29} \gg$.

En conclusión, es cierto que la comedia de Colorado no es un dechado de virtudes, ni cabe leerla como la mejor adaptación de la novela ejemplar cervantina. Sin embargo, su Rinconete y Cortadillo atesora algunos méritos más que sobresalientes como considerarla un loable intento de versificar su modelo. Sin duda, es una muestra muy ilustrativa, desde la perspectiva de la historia literaria, de cómo se han leído las obras de Cervantes a lo largo del siglo diecinueve, y cómo afloran siempre en las plurales relecturas cervantinas de todas las épocas las innatas propiedades dramáticas de sus textos.

En este caso, caprichosa e irónica resulta la historia para quien tuvo una suerte desigual con el teatro.

\section{BIBLIOGRAFÍA CITADA}

Arellano, Ignacio (2012). «Recreaciones cervantinas: invenciones y quimeras de Don Quijote», en Carlos Mata Induráin (ed.), Recreaciones teatrales y alegrías cervantinas. Pamplona: Universidad de Navarra, pp. 11-21. 
Blanco Aguinaga, Carlos (1957). «Cervantes y la picaresca. Nota sobre dos tipos de realismo», Nueva Revista de Filología Hispánica. 11, pp. 313-342. https://doi.org/10.24201/ nrfh.v11i3/4.1334.

Casalduero, Joaquín de (1943). Sentido y forma de las «Novelas ejemplares». Buenos Aires: Revista de Filología Hispánica.

Cervantes, Miguel de (2001). Novelas ejemplares, estudio introductorio Javier Blasco, ed. Jorge García López. Barcelona: Crítica.

Cervantes, Miguel de (2016). Poesías, ed. Adrián J. Sáez. Madrid: Cátedra.

Colorado y Martínez, Vicente (1897). Teatro. Volumen I. Precedido de una carta de D. Pedro Antonio de Alarcón y de una crítica de D. Manuel Cañete. Madrid: Ricardo Fe.

Colorado y Martínez, Vicente (1901). Rinconete y Cortadillo. Comedia en tres actos y en verso, sacada de la novela ejemplar de Cervantes. Madrid: B. Rodríguez Serra.

Escudero Baztán, Juan Manuel (2013). «Reescrituras dramáticas áureas de La fuerza de la sangre de Cervantes», Anales Cervantinos. 45, pp. 155-174. https://doi.org/10.3989/ anacervantinos.2013.007.

Escudero Baztán, Juan Manuel (2014). «Autoridad, autores y editores en La desordenada codicia de los bienes ajenos de Carlos García», Lejana. Revista crítica de narrativa breve. 7.

Escudero Baztán, Juan Manuel (2016). «De huellas y sucedáneos quijotescos en los entremeses del Siglo de Oro», Alpha. 43, pp. 191-203. https://doi.org/10.4067/s071822012016000200013.

Fernández Ferreiro, María (2011). «Adaptaciones teatrales del Quijote (Siglos XX-XXI). Selección de un corpus», en Carlos Mata Induráin y Adrián J. Sáez (eds.), Scripta Manent. Actas del I Congreso Internacional Jóvenes Investigadores Siglo de Oro. Pamplona: Universidad, pp. 185-194.

Fernández Mosquera, Santiago (2005). Quevedo: reescritura e intertextualidad. Madrid: Biblioteca Nueva.

García, Carlos (1996). La desordenada codicia de los bienes ajenos, ed. Víctor Roncero López. Pamplona: Eunsa.

García López, Jorge (1999). «Rinconete y Cortadillo y la novela picaresca», Cervantes: Bulletin of the Cervantes Society of America. 19 (2), pp. 113-124.

Gómez de Baquero, Eduardo (1901). Reseña al estreno de Rinconete y Cortadillo de Vicente Colorado, La España Moderna. 13 (150), pp. 141-145.

Jurado Santos, Agapita (2005). Obras teatrales derivadas de novelas cervantinas: para una bibliografía. Kassel: Reichenberger.

Lázaro Carreter, Fernando (1978). «Para una revisión del concepto 'novela picaresca'», en «Lazarillo de Tormes» en la picaresca. Barcelona: Ariel, pp. 193-229.

López Estrada, Francisco (1983). «Apuntes para una interpretación de Rinconete y Cortadillo», en José Jesús de Bustos Tovar (ed.), Lenguaje, ideología y organización textual de las Novelas ejemplares». Madrid: Universidad Complutense / Université de Toulouse-LeMirail, pp. 66-67.

López Mozo, Jerónimo (2015). «La narrativa de Cervantes. Reescrituras españolas para la escena (1950-2014)», Don Galán: revista de investigación teatral. 5. Revista electrónica.

Martínez Deyros, María (2015). «El proceso redaccional de Poesías de Miguel de Unamuno: intento de reconstrucción», Artifara. 15, pp. 21-41.

Montero Reguera, José (1993). «Imitaciones cervantinas en el teatro español del siglo XVIII», Actas del tercer coloquio de la Asociación Internacional de Cervantistas. Barcelona: Anthropos, pp. 119-129. 
Montero Reguera, José (2013). «'Miró al soslayo, fuese y no hubo nada'. Fortuna y actualidad de un verso cervantino», Parole rubate. Rivista internazionale di studi sulla citazione / Purloined Letters. An International Journal of Quotation Studies. Speciale Cervantes. 8, pp. 171-186.

Pérez, Dionisio. «Madrid», Nuevo Mundo, Madrid, jueves 6 de abril de 1905, año 12, núm. 587, página 7 .

Quevedo, Francisco de (1993). La vida del Buscón, ed. Ignacio Arellano. Madrid: Espasa Calpe.

Rey Hazas, Antonio (1999). «Cervantes se reescribe: teatro y Novelas Ejemplares», Criticón. 76, pp. 119-164.

Rey Hazas, Antonio (2003a). «Género y estructura del Coloquio de los perros, o cómo se hace una novela», Deslindes de la novela picaresca. Málaga: Universidad, pp. 375-405.

Rey Hazas, Antonio (2003b). «Rinconete y Cortadillo: la picaresca abre las puertas de la mafia», Deslindes de la novela picaresca. Málaga: Universidad, pp. 407-440.

Rodríguez-Gallego, Fernando (2010). «Aproximación a la reescritura de comedias de Calderón de la Barca», en Natalia Fernández (ed.), "Como en la antigua, en la edad nuestra». Presencia de la tradición en la literatura española del Siglo de Oro. Barcelona: Universidad Autónoma, Prolope, TC/12, pp. 157-193.

Rodríguez-Luis, Julio (1980). Novedad y ejemplo de las 'Novelas' de Cervantes. México: Porrúa, 2 vols.

Ruano de la Haza, José M. ${ }^{\text {a }}$ (1998). «Las dos versiones de El mayor monstruo del mundo, de Calderón», en Marc Vitse (ed.), Siglo de Oro y reescritura. I: Teatro, Criticón. 72, pp. 35-47.

Sáez, Adrián J. (2013). «Reescritura e intertextualidad en Calderón: No hay cosa como callar», Criticón. 117, pp. 159-167. https://doi.org/10.4000/criticon.237.

Sánchez, Francisco J. (1993). Lectura y representación. Análisis cultural de las 'Novelas ejemplares' de Cervantes. Nueva York: Peter Lang.

Sanz Cabrerizo, Amelia (1995). «La noción de intertextualidad hoy», Revista de Literatura. 57, 113-114, pp. 341-361.

Senabre, Ricardo (1979). «El Doctor Carlos García y la picaresca», en Manuel Criado del Val (ed.), La picaresca. Orígenes, textos y estructuras. Madrid: Fundación Universitaria Española, pp. 631-645.

Vaiopoulos, Katerina (2010a). De la novela a la comedia: las «Novelas ejemplares» de Cervantes en el teatro del Siglo de Oro. Vigo: Academia del Hispanismo.

Vaiopoulos, Katerina (2010b). «La tradición narrativa en el teatro español del Siglo de Oro. El caso de las Novelas ejemplares de Cervantes», en Natalia Fernández (ed.), «Como en la antigua, en la edad nuestra». Presencia de la tradición en la literatura española del Siglo de Oro. Barcelona: Universidad Autónoma, Prolope, TC/12, pp. 83-119.

Varela, José Luis (1968). «Sobre el realismo cervantino en Rinconete», Atlántida. 6, pp. 434-449.

Ynduráin, Domingo (1966). «Rinconete y Cortadillo: de entremés a novela», Boletín de la Real Academia Española. 46, pp. 321-333.

Zeda [Francisco Fernández Villegas] (1901), «Lecturas de la semana. Rinconete y Cortadillo. Comedia en tres actos y en verso, por Vicente Colorado», La Época, viernes 10 de mayo.

Zeda [Francisco Fernández Villegas] (1904), «Vicente Colorado». Madrid, Nuevo Mundo (Madrid), jueves 22 de septiembre, p. 4. 